\title{
Treasures, trash and tenure: hoarding and housing risk
}

\author{
Michele Slatter* \\ Flinders University
}

\begin{abstract}
Hoarding, whether or not linked with squalor and self-neglect, can exact a high price on the well-being of the hoarder and the resources of agencies that become involved. Although under-researched until recently, both professional and public awareness of hoarding is now on the increase. This is timely, because the indications are that hoarding will become more not less of an issue as tenures, built form and demographics change. This short discussion piece uses four case studies to highlight the relationship between tenure and housing risk. It also identifies the essential challenges that such cases pose and argues that it is time to increase public understanding of compulsive hoarding and to develop recognisable, predictable and holistic responses that address the issue as well as its impact.
\end{abstract}

Keywords: hoarding, tenure, squalor, eviction, nuisance.

\section{Trash and treasure: Four stories}

- Mr Atkinson collected other people's rubbish and kept it at home.

- Dr Hein kept German shepherd dogs; at one time she had as many as 140.

- Mr Ibrahim established a collection of shopping trolleys and regularly added to it.

- Mrs Harben rarely threw out anything she'd used; her flat was full.

Their stories will frame an account of the responses evoked by incidents of hoarding. They are drawn from English and Australian experiences, which in this area seem remarkably similar. This short discussion piece argues that it is time to increase public understanding of compulsive hoarding and to develop recognisable, predictable and holistic responses that address the issue as well as its impact.

\section{The hoarding habit}

According to current research, one in forty of us will have a lifetime issue with hoarding (Somers, 2006). 'The acquisition of, and failure to discard, possessions that appear to 
be either useless or of limited value' (Frost and Gross, 1993) is quite common. It becomes a clinical disorder only when it, or the resulting clutter, presents problems in living (Frost and Gross, 1993). Such 'clinical' hoarders are distinctive both in the volume of material they accumulate and their inability to organise it (Frost, 2004). Their homes may fill with accumulated material to the extent that windows and doors are unusable and movement through the rooms, if possible at all, is by means of narrow 'go paths' between the stacks of 'stuff'. Cookers, fridges, sinks and bathrooms may disappear under the mountains of material and become inaccessible. Such conditions may obviously bring risks (or increased risks) including fire or falls; insanitary conditions; dilapidated premises; poor personal hygiene; poor nutrition; untreated and deteriorating mental and physical health; neighbour disputes and social isolation (Steketee, Frost, Kim, 2001).

Hoarding research is still a relatively new area of inquiry. A systematic review of the literature published in 2004 highlighted the continuing absence of an agreed definition of hoarding and emphasised the importance of individual evaluation in each case (Maier, 2004). Compulsive hoarding behaviour may accompany many conditions, including anorexia, schizophrenia, Alzheimer's disease, dementia and depression. It is most often seen in patients with obsessive compulsive disorder (OCD). However, its classification as a subtype of OCD or a separate disorder is not yet resolved (Wu and Watson, 2005).

While the classification debate continues, for practical purposes Frost's 'risk and function' definition is widely used. This defines hoarding as the excessive collection and retention of any materials to the point that it impedes day to day functioning and creates a hazard or a potential hazard for the individual (Frost and Gross, 1993; Somers, 2006).

\section{Who hoards?}

Hoarding behaviour does not favour a particular gender, age, ethnic background, socioeconomic status, educational/occupational history or tenure. Some early studies suggested that hoarders were 'usually older, socially eccentric, mentally competent females' who were owner-occupiers (Dunn, 1995). More recent studies suggest a broader susceptibility. However, as people age, hoarding issues may become more acute. One poll of agencies serving older adults reported that approximately $10 \%$ of their clients were afflicted with hoarding behaviour (Cornell, 2005). This will include a proportion of clients who display the so-called 'Diogenes syndrome', where compulsive hoarding is accompanied by squalor and self-neglect (Bexon, 2004). Increased age may bring an impaired capacity to cope if physical health and fitness decline, senses are less acute, dementia develops, a partner dies or children move out. It may also bring increased social isolation. So, although hoarding is not understood as specifically age-related, older people living alone are more likely to show problem hoarding characteristics and this group is disproportionately female. Age and social isolation are recurrent factors: factors that are set to increase as populations age, family links become more tenuous and single person households more prominent (Beer et al., 2007).

\section{Hoarding complications}

\section{No quick fix}

The issue of hoarding, its impact and its management present a range of challenges for everyone involved. Some particular features exacerbate the risks it poses not only to 
health and well being but also to the housing security of sufferers. At present there is no 'quick fix' for hoarding. Talking therapies and behaviour therapy are being continually trialled (Skeketee et al., 2003) and there may be some promise from drug trials (Saxena, 2007). However, the four stories mentioned in the opening paragraph can be used to illustrate several features that commonly complicate responses to hoarding situations.

\section{No recognition}

One of the most problematic aspects of compulsive hoarding is that people who hoard may not recognise the behaviour as a source of risk to themselves or others and may decline to engage with agencies that attempt to support them in addressing it. However, they may also feel considerable anxiety and shame about others' response to their property. This can result in increasing isolation and may exacerbate the risk. For example, necessary repairs and maintenance may not be done if tradesmen are not called or are denied access. Similarly, friends, relatives and support agencies may be kept well away, compounding the hoarder's isolation (Dunn, 2006).

Dr Hein's case seems to show this pattern. Dr Hein, a vet, had kept dogs on her property since 1965 . She had 140 or so in the 1990 s but numbers had declined to between 15 and 100 in recent years. Over a period of more than 20 years she was convicted in eight trials on sixteen counts under the Breeding of Dogs Act 1973 and the Protection of Animals Acts 1911-88. In 1996 the Royal College of Veterinary Surgeons (RCVS) removed her name from the professional roll. In 2003, aged 74 and having suffered a stroke, she applied to be reinstated. Her application was refused, as was her second application the following year (RCVS, 2003; 2004). In considering the second application, the RCVS commented that 'she has...repeatedly refused to admit that she did anything significantly wrong, irrespective of...the (guilty) pleas made at the time. This gives us considerable concern that her offences may be repeated in the future' (RCVS, 2004). Legal action brought in 2005 by her local council aimed to prevent her keeping dogs, motivated by a desire to pre-empt further suffering from her 'inadvertent neglect'. Lord Justice Waller found that the council was 'convinced that with the defendant's track record...if the dogs were returned to her, as sure as night follows day, she would continue to breed dogs without a licence'. The council could also foresee that 'the addition of another twenty-seven dogs to those on the premises would give rise to a public nuisance by noise, smell and infestation by vermin. The risk of the dogs being neglected, or ill treated, would be greatly increased'. In the light of the evidence presented, His Lordship found the council's concerns 'understandable' (Guildford Borough Council v Hein [2005] EWCA Civ 979).

Mrs Harben was a more indiscriminate hoarder. She stored paper, newspapers, food, bottles, cat litter and other material in her home. A fire in 1999 was caused, or at least exacerbated, when a candle fell and ignited some of the combustible material heaped up throughout her flat. Subsequently, insurance assessors spent a day steadily clearing away detritus before they found the bathroom and toilet. Mrs Harben later refilled the flat so that access to the bathroom was again lost. Like Dr Hein, Mrs Harben resisted all approaches made to her about the state of her premises. Environmental Health officers had to force entry, in accordance with their statutory powers. They cleaned up the premises. There was no evidence of any follow-up engagement by Mrs Harben with her doctor, Social Services or her landlord. They were all apprised of the situation (Castle de Joncaire v Harben LVT 10 January 2007).

On the other hand, this attitude is by no means universal. Mr Ibrahim maintained a precarious mental stability that could be disturbed by stress. Stress intensified his propensity to collect shopping trolleys and could also cause him to seem somewhat volatile. He alone of the four people featured seems to have had active and effective 
support networks in place. He acknowledged that he suffered from 'severe psychological and personality disorders, including Obsessive \& Compulsive Disorder (sic)' and he emphasised the importance to him of support networks in helping him maintaining his independence (Department of Housing $v$ Ibrahim [2003] NSWCTTT 293).

\section{No deterrence}

Mr Atkinson had already been prosecuted twice for breaching notices served under s 80 of the Environmental Protection Act 1990 before receiving a two year anti social behaviour order on conviction (a CRASBO) in late 2004 (Atkinson, 2004).

In addition to the various criminal actions brought against $\mathrm{Dr}$ Hein, she had also been served with a range of notices under the Environmental Protection Act 1990, the Public Health Act 1936 and the Prevention of Damage by Pests Act 1949. Most recently, in 2005, the local council alleged that 'over the past 10 years (she has) demonstrated a determination to avoid compliance with legislation which affects her care, ownership, possession and management of dogs' (Hein para 54). In 2005, council officers advised the local council that 'progress has been made in reaching a conclusion on this case' (Bell, 2005). By then the council had incurred costs of approximately $£ 160,000$ (not including legal expenses) and there was actually no guarantee that the 'conclusion' would be final.

The local council's Environmental Health Department twice cleared out Mrs Harben's flat in the period 2000-05 'with no long-term impact on conditions in the premises.'

Mr Ibrahim found himself subject to legal action for 'unacceptable behaviour' throughout the period 2001-3 and despite clear efforts to modify his behaviour, nevertheless continued to occasionally alarm and disturb his neighbours (Ibrahim, 2003).

\section{No engagement}

Legal action threatened serious consequences for each of these hoarders. Mr Atkinson was potentially at risk of prison and a criminal record; Dr Hein was at risk not only of a criminal record but also of publicity and professional exclusion; Mr Ibrahim and Mrs Harben both risked the loss of their home. However, only Mr Ibrahim was able to respond to the risks that he faced. Dr Hein seems to have treated the various cases brought against her over the years with minimal attention. Presumably to save time and trouble, she pleaded guilty to all charges in the earlier cases. In the most recent litigation, when there was a real risk she might lose her dogs, she did not seek professional assistance, but represented herself at first instance. On appeal she did have professional advice and representation, but only through pro bono interventions by the solicitor and counsel concerned.

Mrs Harben did not engage with the legal case against her. She submitted no written response when directed to, she did not appear on either of the occasions when her case was being heard and she did not acknowledge or accommodate a site visit made to her premises in the course of the hearing.

Mr Ibrahim, on the other hand, had well-briefed support and representation at his hearing from a tenancy advice service. As mentioned above, he was also committed to social and support networks that helped him maintain an independent life. 


\section{Housing risk: tenure counts}

The circumstances of these four people passed into the public domain because in each case legal action was instituted against them as a result of the impact of hoarding on their neighbours (and in Dr Hein's case, on her dogs).

Mr Atkinson and Dr Hein were both the focus of legal action that aimed, essentially, to deter their behaviour. Mr Atkinson's collection of rubbish seems to have created a public health hazard. Dr Hein's activities not only endangered the dogs but inflicted noise and smells on a neighbouring property. She was also reported to have dumped noxious waste on adjoining land belonging to the council. The council took action. She could equally have been sued by her neighbours in private nuisance. The likely outcome then would have been an injunction, limiting and defining her use of the land and her activities on it.

Neither Mr Atkinson nor Dr Hein faced the threat of losing their home. On the other hand Mrs Harben and Mr Ibrahim faced precisely that risk as a result of their hoarding.

Mrs Harben owned a leasehold flat. Her upstairs neighbour, Ms Castle, had purchased the freehold of the building (making her Mrs Harben's 'landlord'). She was now seeking to terminate Mrs Harben's lease. Ms Castle alleged that part of her own flat was unusable because of the smell from Mrs Harben's home below. She also claimed that, since the fire in late 1999, she had become anxious about the risk of further fires, given the amount of combustible material below and the apparent disorder in which it was kept. Her case against Mrs Harben was based primarily on an alleged breach of the leasehold covenant to 'maintain' her flat and the action was successful. In due course, Mrs Harben may be evicted, losing her home and the value of a major asset in the process. In many cases legal actions are threatened or instituted 'strategically', to provoke the other party to agree a compromise solution without going to court. However, in cases like this there seems little hope for an agreed compromise if the hoarder is not able to change their behaviour and cannot engage with the case.

Mr Ibrahim also faced eviction because of his behaviour. He was a public housing tenant. His neighbours complained about him to their common landlord, the public housing authority, which began eviction proceedings under a provision of his tenancy that forbids any 'nuisance or annoyance' or 'inappropriate behaviour' towards neighbours. As mentioned above, Mr Ibrahim had the support of a tenant advocate and a range of support networks. The Tribunal found that he had behaved inappropriately on one occasion. They commented that 'returning home late at night or in the early hours of the morning pushing a trolley full of shopping and engaging in loud, abusive conversations (even if only with oneself) is inappropriate'. However, they doubted much of the remaining evidence against him and, indeed, found that Mr Ibrahim had had to endure bullying, taunting and a serious assault perpetrated by the very neighbours who had complained. The Tribunal declined to terminate his tenancy, saying that this was not an 'appropriate matter' for such an order. His advocate had demonstrated $\mathrm{Mr}$ Ibrahim's 'willingness to behave more appropriately' and his 'ongoing commitment to saving his tenancy'. The Tribunal also noted that, having lived in this home all his life (37 years), 'his psychological and personality disorders would not be assisted by being forced to move away...(They) would not assist him in establishing a shared tenancy where he had to live in close proximity with one or more persons. His income will not allow him to rent similar premises in this area or indeed in any area in the ... region. His ties with the area in respect of family, health care needs and support services are strong and established.' 
The Tribunal commented: 'That Mr Ibrahim is somewhat different ought not to be sufficient reason for his neighbours to be less than tolerant of him.'

Had he been evicted, Mr Ibrahim's housing prospects would have been bleak. Eviction from public rental would render him ineligible for another public housing tenancy. Cost alone would have forced him to move away. Loss of his support networks would severely compromise his chances of obtaining and successfully maintaining a tenancy in the private rental market. If he were then evicted from private rental the details would probably have been entered on a 'tenant blacklist', effectively destroying his chances of future private rental opportunities. He could have spent years falling between public housing, private rental, boarding houses and homelessness (Beer et al 2006).

The case studies illustrate an unfortunate but essential point about hoarding: tenure counts.

\section{A spectrum of tenures}

As A Life of Grime's celebrity hoarder Mr Trebus illustrated, hoarders who own the freehold of their home are in a strong position: they are unlikely to lose their home as a result of their hoarding. They may be subjected to injunctions if neighbours sue in nuisance. They may have to endure forcible incursions by environmental health officers, in the public interest. The cost of clean-ups may be registered as a charge against the title of their home. There is a very remote possibility that in truly extreme cases their property could be condemned or they could be sent to prison for contempt if injunctions are not obeyed. However, assuming they remain legally competent, these are the only risks they run. Traditionally owner/hoarders may also have been advantaged by having more space than renters, more distance from neighbours and more privacy, all of which could reduce or delay 'public' concerns.

However, hoarders who are tenants or who own leasehold flats are vulnerable to losing their homes. They may be evicted because their behaviour may constitute a breach of standard covenants concerning condition, maintenance, repair or 'nuisance'. Their home may be in very close proximity to neighbours. This increases the risks to neighbouring properties from the hoarding: fire risk, load risk on floors/ceilings, possible infestation, smells and detritus, loss of amenity and possible reduction in value. Proximity also reduces privacy and makes more conspicuous the hoarder's behaviour, or the results of it. The risk of action against the hoarder is thus greater. This is especially true in blocks of flats, converted houses, rental retirement developments and small townhouse developments: all likely homes for single person households where hoarding risk may materialise. Landlords, agents and property managers may become entangled in hoarding cases as well as the residents.

If clinical hoarding occurs in strata title, community title or commonhold property, the byelaws or commonhold community statement are likely to include provisions broadly similar to lease terms concerning repair, maintenance and nuisance. Hoarding may breach these and result in conflict between occupiers, represented by the strata corporation, community corporation or commonhold association. Experience of strata title hoarding disputes highlights their relative frequency, their sensitivity and their complexity (Port Philip, 2005). Again, proximity works to the disadvantage of all parties. Disputes in these tenures are normally resolved by conciliation. Loss of the home is only a remote possibility here but routes to resolution in hoarding cases are far from clear. 


\section{Evolving tenures}

Tenure is not static. It evolves. New demands result in new templates. Factors such as housing (un)affordability, increasing density of development, increasing numbers of single person households, an ageing demographic, changing expectations of continued independence and policies that support ageing in place all continue to encourage the development of new 'ownership' models. They have prompted the development of financial products such as reverse mortgages (equity release loans), shared equity loans, rent to buy arrangements and property options that include rental retirement developments, community titled/commonhold apartments, master planned and gated communities. All these modify traditional 'ownership', and infuse 'ownership' tenures with aspects of rental. This usually opens the door to potential control over aspects of the 'owner's' behaviour that have not been encountered in traditional 'ownership'. Mrs Harben's case in particular gives pause for thought, especially as tenure evolution will continue.

\section{Evolving responses to hoarding and housing risk}

Public awareness of clinical hoarding as a condition has undoubtedly been assisted by programmes such as A Life of Grime and the Oprah Winfrey Show. Public awareness of mental illness and tolerance of it are reported to be increasing in both the UK and Australia. Nevertheless, the popularity of lifestyle TV, a deep concern with property values and a suspected under-reporting of antagonism to those whose behaviour visibly deviates from the conventional all suggest that, fear, mockery and antagonism will continue to be usual responses to hoarders. Cases of compulsive hoarding may be felt to damage the amenity of a neighbourhood, spoil the neighbours' enjoyment of their property and threaten the value of local real estate. As we saw with Mr Atkinson, hoarding can be treated as anti social behaviour. The external impact of hoarding may distract from the hoarder's issue of hoarding.

The challenge for agencies and professionals in such cases is significant. Not only must they diligently maintain the boundaries between 'lifestyle choice/mere eccentricity' and 'disfunction'. They may also have to hold the line between apparently incompatible agendas. Neighbours are often vocal and passionate. They may have already engaged the attention of political or media interests whose contributions can complicate sensitive client-centred work. The occupier at the centre of the matter may be much less assertive. Issues of autonomy, capacity and self-determination must be addressed and the balance of private and public interest maintained. This is especially challenging in a climate which can confuse the 'different' with the 'dangerous'. It is instructive to note that of the four cases described, only Mr Ibrahim had effective support networks. It may not be a coincidence that he also had appropriate advocacy support in his eviction case, which he won. Unfortunately, research has shown how unusual this is. When faced with a looming legal problem most people (especially those who are disadvantaged) do not seek or access specialist support, nor do they engage with the situation themselves, usually to their detriment (Nixon et al., 1996; Pleasance, 2004; Slatter and Beer, 2003; Beer et al., 2006).

Environmental health officers play a leading role in many cases, drawn in through their statutory powers. The new guidelines on management of hoarding cases promised by the Chartered Institute of Environmental Health will be a valuable and welcome resource. However, environmental health workers are not alone. Major landlords, particularly public landlords and housing associations, also encounter hoarding cases regularly. Mental health agencies, district nurses, social services staff, 
domiciliary care workers, fire officers, Meals on Wheels volunteers: all may become involved. Strata/community corporations and commonhold associations and their managing agents also need appropriate strategies in place.

Protocols are needed for hoarding cases that articulate intervention criteria, respect the rights of the client/tenant/resident at the centre of the case, delimit the boundaries of intervention and identify the legal responsibilities of agencies. They need to facilitate collaborative responses. Informal liaison is the way in which many local agencies are already working to address the complexities of hoarding cases sensitively and effectively. Social housing managers, whose professional practice embraces both property and tenant management skills, are well placed to develop such networks and collaborations.

However, it's time to move on from informal collaboration (Wesley, 2007). Moves to develop appropriate and formalised inter-agency protocols are increasingly evident (Merkel, 2007; McDermott, 2007). Increased public awareness and improved agency responses can also be promoted by a 'visible' entity that names the condition, assumes its occurrence; embodies a preparedness of response and provides a point of contact and source of information. In the United States an increasing number of local authorities host a Hoarding Task Force. These Task Forces comprise a wide range of participant stakeholders. Their profile varies but the Fairfax County Hoarding Task Force, Virginia, is an inspiring example that provides web-accessible public information, referral options and resources (Fairfax County, 2006). Neither the United Kingdom nor Australia has yet developed such Hoarding Task Forces. Together with professional protocols and practical training on hoarding management they need to become a feature of the landscape.

The indications are that hoarding will become more, not less, of an issue as tenures, built form and demographics change. Hoarding can exact a high price on the well-being of the hoarder and on the resources of agencies that become involved. In the interests of individual and community well being, the responses to hoarding need to evolve, through public understanding and professional collaboration. In future, the issue as well as its impact, should be centre stage.

* Correspondence Address: Michele Slatter, School of Law, Flinders University, GPO Box 2100, Adelaide 5001, Australia. Email:michele.slatter@flinders.edu.au.

\section{References}

Atkinson v Barking and Dagenham (2004) Environmental Health News, 48, 10 December, 1.

Beer, A. (2007) 21st Century Housing Careers and Australia's Housing Future. Melbourne: Australian Housing and Urban Research Institute.

Bell, C. (2005) Amberwell Kennels, Newlands Corner, Shere. Guildford Council Executive, 12 October.

Bexon, T. (2004) Mental health. Environmental Health Journal, October, 302-04. Weill Medical College of Cornell University, Clutter and Hoarding at http://www.cornellaging.com/gem/hoarding index.htlm accessed 27/07/06

Dunn, M. (2006) First Person. Saturday Guardian, 08.07.06.

Dunn, R. (1995) Extreme Homeowners. Caring, 14, 7, 36-8.

Frost, R.O. and Gross, R.C. (1993) The hoarding of possessions. Behav Res Ther, 31, 367-381. 
p.36. Treasures, Trash and Tenure: Hoarding and Housing Risk

Farifax County Hoarding Task Force materials via http://www.fairfaxcounty.gov/dpwes/trash/hoarding/tf general.htm accessed 27/07/07.

Maier, T. (2004) On phenomenology and classification of hoarding: a review. Acta Psychiatrica Scandinavia, 110, 5, 323.

McDermott, S. C. (2007) Self Neglect and Squalor among Older People: the Ethics of Intervention - Ph.D Thesis. School of Social Science and International Studies, University of New South Wales.

Merkel, J. (2007) The Role of Agencies in Response to Clients with Obsessive Compulsive Hoarding Disorder and the Development of an Agreed Interagency Protocol - Thesis for Master of Psychology (Clinical). School of Psychology, University of Adelaide.

Nixon, J. and Hunter, C. (1996) Housing Cases in the County Courts. Policy Press.

Pleasance, P., Buck, A., Balmes, N., O'Grady, R., Genn, H. and Smith, M. (2004) Causes of Action: Civil Law and Social Justice: Final Report. London: Legal Services Commission.

City of Port Phillip (2005) Submission to the Senate. Select Committee on Mental Health, City of Port Phillip.

Decisions of the Royal College of Veterinary Surgeons re Helen Elisabeth Hein 12 September 2003; 20 July 2004.

Saxena, S., Brady, A.L., Maidment, K. M., Baxter, L. R. (2007 in press) Paroxetine treatment of compulsive hoarding. Journal of Psychiatric Research, 41, 6, 481-7.

Slatter, M. and Beer, A. (2003) Housing Evictions: A South Australian Study. Adelaide: Australian Council for Community Services Research.

Somers, S. (2006) Understanding hoarding behaviour (DVD). New York: Training Strategies Group SUNY.

Steketee, G., Frost, R., and Kim, Hyo-jin. (2001) Hoarding by elderly people. Health and Social Work, 26, 3, 176-184.

Steketee, G., Frost, R. and Kyrios, M. (2003) Cognitive Aspects of Compulsive Hoarding. Cognitive Therapy and Research, 27, 4, 463-479.

Wesley Mission (2007) Living with Mental IIIness: Attitudes, Experiences, Challenges. Sydney: Wesley Mission.

Wu, K. and Watson, D. (2005) Hoarding and its relation to obsessive-compulsive disorder. Behav Res Ther 43, 7, 897. 